\section{Castration pleases bulls?}

\section{New Delhi}

A vaCCINE that sterilizes bulls, developed by biotechnologists at the National Institute of Immunology (NII) at New Delhi, is to be used as a key tool in India's campaign to boost milk production.

Tests carried out at government farms have shown that bulls become 100 per cent sterile within four weeks of a single injection into the testis. The sterility produced is said to be permanent.

India's programme for cattle improvement rests primarily on artificial insemination of cows and buffalos using semen of high-quality exotic bulls. Last year alone, nine million cows were inseminated artificially at India's network of 15 semenfreezing stations, 52 frozen-semen banks, and 5,500 artificial insemination centres. But the AI programme has so far failed to make impact, one major reason being that the cows are impregnated by local bulls before the arrival of semen from semen banks. The NII vaccine will now be used to sterilize these interfering bulls. The cost of sterilizing an animal is said to be less than one rupee.

Trials have begun in Bhoosali, a village in Haryana state bordering Delhi. Local bulls in the village have been sterilized with the injectible vaccine, and the National Dairy Research Institute (NDRI) is planning to extend the work to 30 more villages in the state. If the experiments are useful, sterilization will be taken up on a national scale. The idea, according to an NDRI spokesman, is gradually to improve the stock of Indian cattle. Out of the estimated 180 million cows and 64 million buffalos in the country, two-thirds are of non-descript quality.

Traditionally, Indian villagers used to sterilize poor quality bulls by mechanically crushing the spermatic cord. Apart from being cruel and painful, this method also led to total loss of libido thereby depriving the bulls of their ability to detect females on heat. The vaccine has no such effect. For AI to be successful, it must be done within 48 hours of ovulation and bulls, rather than veterinarians, are the best detectors of this crucial period.

The NII has not disclosed the composition of the vaccine except that it is based on BCG (Bacillus Calmette-Guerin) used for tuberculosis prevention. It relies on eliciting an immune response at the site of sperm production. Trials in rats, guinea pigs, rabbits, dogs and monkeys had shown that BCG injected into the testis could block spermatogenesis without the loss of androgens. According to NII, the technique works in all mammals without producing any adverse side-effects.

K.S. Jayaraman

\title{
Soviet space agency seeks first foothold in tough Western market
}

\section{London}

THE Soviet Union seems to have made its furthest progress yet in its attempt to break into the lucrative market of commercial space launches with the signing of preliminary agreements with three Western companies. But the initiative is unlikely to proceed further unless the United States relaxes its virtual embargo on the transport of US technology to the Eastern bloc - almost all Western-made satellites contain components from the United States.

The latest efforts by the Soviets to force a change in the rules were disclosed in London last week when representatives from the Soviet foreign trade organization Licensintorg and the two-year-old civil

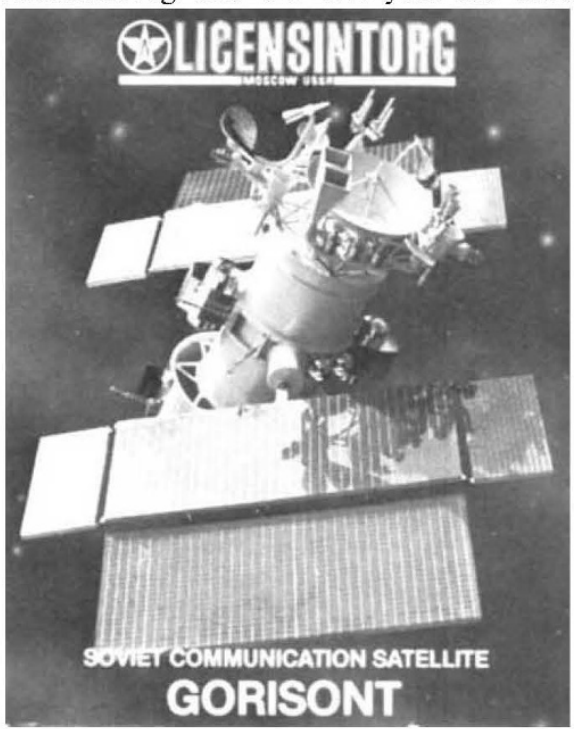

Hard sell - a glossy brochure Soviet-style

space agency Glavkosmos briefed British industrialists on the full range of services available. London-based Jardine Insurance Brokers has been signed up "to market Soviet launch vehicles to commercial communications companies in Europe and newly industrialized countries".

There is little dispute that the Soviets are offering a commercially attractive deal - a two-tonne payload can be placed in geostationary orbit for between $£ 18$ million and $£ 20$ million, launched by the reliable Proton vehicle (with an impressive record of only nine failures from 104 launches between 1970 and 1987), representing an undercutting of Western rates by between one-half and one-third. Similarly favourable insurance arrangements are available through the Insurance Company of the USSR (Ingosstrakh) Ltd.

The Soviets are keen to dispel any fears about the security of payloads. The launch package enables the customer to accompany the payload at all stages, from chartering an Aeroflot flight from the country of origin direct to the Baikonur launch site (waiving normal customs regulations), to seeing the equipment on board the launch vehicle. Much is made of the facilities available to foreign technicians escorting the payloads, including "comfortable rooms, restaurant, wine bar, swimming pool and sauna".

Maurice Brackenreed Johnston, deputy chairman of Jardine, seems confident that the three companies who have signed preliminary agreements will have their satellites in orbit within three years. "We went into this with the full knowledge of all the difficulties we were going to encounter and the length of time it was going to take us to develop this relationship", Johnston said last week.

The chief obstacle to the Soviet Union's entry into the global launching business comes from the United States International Traffic in Arms regulations, section 126.1, which specifically forbids the transport to the Soviet Union of any technology of US origin without prior agreement from the State Department, which has made it abundantly clear in the recent past that such permission will be refused.

Within the past 18 months the Soviet government has made official representations to the White House urging a relaxation of the rules and Glavkosmos has lobbied satellite manufacturers anxious to clear their mounting backlog ("dangling fat carrots before their eyes and waiting to see what the outcome would be", according to one sceptical State Department source). So far the outcome has been negative and officials see little indication of any change in the near future.

Furthermore, it is suspected that the Soviet commercial launch programme would be heavily subsidized. Last week the Soviet delegation in London was obviously aware that this thought was likely to be occurring to people at the meeting; without prompting, its chief spokesman, Evegeni Louppov, a senior engineer with Licensintorg, said how an agreement had not been signed with one Western company which was not prepared to pay the rate required for Glavkosmos to realize a sufficient profit. For the Soviets - and Jardine - the US regulations have little to do with the transfer of technology and a lot to do with protecting the interests of Western launch vehicle manufacturers.

As launch orders continue to accumulate in the West, political pressure on the US government to let the Soviet Union into the launch market is certain to increase. Just how long it will be before the wine bar at Baikonur serves its first party of Western technicians remains to be seen.
Simon Hadlington 